Research Article

\title{
Experimental Research on Frost Heave Characteristics of Gravel Soil and Multifactor Regression Prediction
}

\author{
Xiaoyong Long $(\mathbb{D}$, Guoping Cen $(\mathbb{D}$, Liangcai Cai, and Yue Chen $(\mathbb{D})$ \\ Aeronautics Engineering College, Air Force Engineering University, No. 1, Baling Road, Baqiao District, Xi'an, China \\ Correspondence should be addressed to Xiaoyong Long; 18509270709@163.com
}

Received 16 April 2018; Revised 16 July 2018; Accepted 25 October 2018; Published 12 December 2018

Academic Editor: Antonio Caggiano

Copyright (c) 2018 Xiaoyong Long et al. This is an open access article distributed under the Creative Commons Attribution License, which permits unrestricted use, distribution, and reproduction in any medium, provided the original work is properly cited.

Gravel soil is usually considered to be insensitive to frost heave. However, many frost heave deformations of foundation in seasonal frozen region indicate that gravel soil may also produce frost heave under certain special conditions. In order to gain a deep insight into the frost heave characteristics of gravel soil, a series of laboratory experiments on one-dimensional frost heave were conducted under the open- and closed-water replenishing condition using an improved experiment apparatus. The influence of various factors including initial moisture content, clay content, compactness, overlying load, and water replenishing on frostheaving ratio of gravel soil were analyzed. And the basic frost heave characteristics including frost heave amount, frost heave speed, frozen depth, freezing speed, and moisture content distribution after freezing in a gravel soil sample were analyzed. The corresponding mechanisms were also discussed. Results showed that in the open water replenishing condition, there exists a linear relationship between initial moisture content, overlying load, and frost-heaving ratio and a quadratic polynomial relationship between clay content, compactness, and frost-heaving ratio. Frost-heaving ratio in the open water replenishing condition can be found to increase over three times than that under the closed water replenishing condition. Multifactor regression empirical formula was obtained by multiple regression analysis to predict the frost-heaving ratio of gravel soil under certain collocation of factors and levels under the closed water replenishing condition. The significant effects on frost-heaving ratio were, in order, water replenishing $>$ initial moisture content $>$ clay content $>$ compactness $>$ overlying load.

\section{Introduction}

Coarse-grained soils, which can show outstanding performance in compaction, shearing intensity, water permeability, and liquefaction under dynamic load, and having the advantages of rich reserves, easy access, and economical, are widely used as natural foundation materials in foundation engineering construction such as highways, railways, airports, dams, and excavations. Traditionally, coarse-grained soils are usually identified as frost heave insensitive materials because of the large grain size, small grain surface energy, weak hydrophilic performance, little film water, large porosity, unapparent capillarity, and weak water migration, and water is easy to freeze into ice in situ [1-4]. However, based on the observation of frost heave of subgrade of Harbin-Dalian high-speed railway in Northeast China and pavement structure foundation of Guoluo Airport located at Qinghai Airport, China, Liu et al. [5, 6], Zhang [7], and
Liu et al. [8] found that the coarse-grained soils can also produce obvious frost heave phenomenon under the combination of certain clay content (the mass fraction of the particle with a diameter less than $0.075 \mathrm{~mm}$ ), initial moisture content, and temperature in seasonal frozen region. Thus, it is significant to comprehensively research the frost heave characteristics of coarse-grained soil for effectively preventing frost heave deformations of coarse-grained soil foundation.

It has always been a focus and hot spot to conduct research on soil frost heave characteristics. Since Everett [9] proposed the first frost theory and Miller [10] put forward second frost theory, there has been a lot of research [11-19] in frost-heaving mechanism, and achieved certain results. With the deepening of the understanding on frost-heaving mechanism in permafrost, the frost-heaving fillers, especially the frost heave characteristics of the coarse-grained soil, are also studied. After that, in 1988, the experimental studies of Chen et al. [20] showed that in the open water replenishing 
condition, the frost-heaving ratio of sand gravel increases with the decreased freezing rate as a power function, because it favours cryosuction $[21,22]$. Also, as a small amount of powdered clay was mixed into the sand gravel, the frost heave sensitivity of gravel in the open water replenishing condition increases with the increase of particle viscosity. Vinson et al. [23] and Chen and Wang [24] have found that the increase in the content of fine-grained soil and the content of clay minerals will increase the frost heave sensitivity of the coarse-grained soil. Among them, Vinson et al. [23] further studied the influence of fine particle size on the frost-heaving susceptibility of coarse-grained soil, established the correlation between frost-heaving ratio and segregation potential, and then pointed out that the smaller the particle size, the greater the correlation coefficient. Through laboratory experiment, $\mathrm{Xu}$ [25] pointed out that when the content of powder and clay in granular soil is less than $12 \%$, even under full water saturation condition, the frost-heaving ratio is no more than $2 \%$. As the content of powder and clay are greater than $12 \%$, the frost-heaving ratio increases obviously. Viklander [26] has found that porosity is an important factor affecting the frost heave when researching the frost heave characteristics of the rocks in the freeze-thaw cycle. Konrad and Lemieux $[27,28]$ thinks that when the content of fine-grained soil in coarse-grained soil is less than $7 \%$, the frost heaving of coarse-grained soil is relatively small, but the amount of water supplement is very obvious, and the frost-heaving ratio of $1 \%$ is the standard to distinguish frost heave sensitivity of coarse-grained soil by laboratory freezing tests. Arenson and Sego [29] determined the position of unfrozen water film during the freezing process of coarse-grained soil by using the fluorimetric tracing method. According to the classification characteristics of railway subgrade filling material and the criterion of maintenance for railway track, Ye et al. [30] pointed out that gravel with fine grain content less than $15 \%$ belong to frost heave insensitive materials and can be used to build the antifreezing layer of subgrade. Lai et al. [31] studied the frost heave and thawing characteristics of a new type embankment and coarse-grained embankment. Through the indoor frost heave experiment, Nie et al. [32] pointed out that the frost heave characteristics of graded crushed stone as the filler on the surface of the foundation bed were affected by moisture content, porosity, and fine particle content, and the moisture content was the dominant factor affecting the frost heave of graded crushed stones. Through the orthogonal experiment and grey correlation analysis of gradation crushed stone in the cold region, Zhao et al. [33], and Wang et al. [34] pointed out that the main factor affecting the frostheaving ratio of graded crushed stones was moisture content, followed by fine particle content, compactness, and cold end temperature and the correlation degree between them was not significant.

To sum up, the combination of some factors and levels of coarse-grained soil also produces certain frost heave. The factors affecting the frost heave of coarse-grained soil include the following aspects: the gradation of soil particles, the content of fine particles and their mineral composition, water content, density, permeability coefficient, capillary action, and external load [35-37]. However, the research results on the impact laws of various factors on the coarsegrained soil frost heaving and its interpretation differ greatly. In particular, the understanding of frost heave characteristics under various factors is not clear enough. Further research is needed on the interaction and correlation between various factors on frost-heaving ratio of coarsegrained soil. The relationships between the research results and the actual engineering need to be strengthened. Therefore, it is necessary to systematically research the frost heave characteristics of coarse-grained soil. The research group has devoted to the research of frost damage in seasonal frozen region of Qinghai-Tibet Plateau for many years, especially the systematic and continuous monitoring of frost heave in gravel soil foundation of Guoluo airport pavement structure $[8,38]$. Therefore, the gravel soil in the seasonal frozen region of Qinghai-Tibet Plateau was selected as the representative research object to research the frost heave characteristics of coarse-grained soil. Based on the unique climate and soil characteristics of the area (see the 2.1 section in detail), a series of laboratory experiments on the frostheaving ratio of gravel soil were carried out, under the openand closed-water replenishing conditions using an improved experiment apparatus, to research the frost heave characteristics systematically. The influence laws of factors including initial moisture content, clay content, compactness, overlying load, and water replenishing on frost-heaving ratio were summarized and discussed. And the basic frost heave characteristics including frost heave amount, frost heave speed, frozen depth, freezing speed, and moisture content distribution after freezing in a gravel soil sample were analyzed and discussed. In order to predict the frost-heaving ratio of gravel soil under certain collocation of factors and levels under the closed water replenishing condition, the multifactor regression empirical formula was obtained by multiple regression analysis. Finally, effective suggestions were put forward for frost heave prevention and control of coarse-grained soil in seasonal frozen area.

\section{Materials and Methods}

2.1. Soil Samples Preparation. Guoluo Airport, which is located in Qinghai-Tibetan Plateau seasonal frozen soil region, was chosen as the research background and prototype in this paper [39]. The climate of Guoluo Airport is characterized by low air temperature (the annual average temperature is about $-4^{\circ} \mathrm{C}$ ), Abundant rainfall (snow) (the annual average precipitation is $400-760 \mathrm{~mm}$, and the annual precipitation days are 118-175 days), long negative temperature period (even more than 8 months), large frozen depth (the maximum frozen depth is about $2.5 \mathrm{~m}$ ), small cooling rate, and long retention time of freezing fronts in soil. Accordingly, this kind of regional climatic condition is apt to intensify moisture migration and frost heave. All soil samples were collected from the field experiment section at Qinghai Guoluo Airport. The filling section of Guoluo Airport was mainly filled with natural gravel soil, but as usual in a construction process, some surface silt can be mixed in, leading to an uneven distribution of clay content. 
Because there were some difficulties of taking, transportation, and saving of undisturbed soil samples, this research adopted the reshaping disturbed soil by bagging, freight, impurities filtration, and air dry. We chose the natural gravel soil as the major experiment subject and selected the surface silt as the reference object. Through the screening test, the clay content of natural gravel soil is $6.9 \%$ and the clay content of surface silt was $50 \%$. The average clay content of the soil base of Guoluo Airport pavement was $9.7 \%$, the clay content of some measured points even reached about $20 \%$. Therefore, we chose four kinds of clay content $10 \%, 15 \%, 20 \%, 25 \%$ to study the effect of clay content on frost heave characteristics of gravel soil and choose $45 \%$ as a comparison group. Five kinds of soil samples with clay content of $10 \%, 15 \%, 20 \%, 25 \%$, and $45 \%$ were obtained by mixing the two soil samples (natural gravel soil and surface silt) uniformly according to the different proportions.

2.2. Physical Characteristics Test of Gravel Soil. According to the test requirement (Test Methods of Soils for Highway Engineering), the grading curve of the above two soil samples was obtained by the grain size analysis test which is shown in Figure 1. It is known from Figure 1 that the content of fine particles in natural gravel soil is less, while the fine particle content in surface silt is more. Moreover, it could be obtained that the coefficient of nonuniformity and the curvature of natural gravel soil (the values are 47 and 2.1) are all larger than that of surface silt (the values are 25 and 1.4). The coefficient of nonuniformity of surface silt is not less than 5 and the curvature is between 1 and 3 , indicating that the gradation of surface silt is good. However, the coefficient of nonuniformity of natural gravel soil is too large, indicating the absence of intermediate particles and the bad gradation. In the actual construction process, the surface silt tends to be doped in natural gravel soil and not only makes the clay content of soil foundation increased, but also to some extent to fill the missing natural gravel soil middle diameter. This effect makes the frost-heaving phenomenon of grit soil foundation more serious.

According to the methods described in Soil Samples Preparation, five kinds of soil samples containing 10\%, 15\%, $20 \%, 25 \%$, and $45 \%$ silt were prepared, respectively, and the results are shown in Table 1. From Table 1, it could be obtained that the optimum initial moisture content increased with clay content while standard maximum dry density decreased with clay content.

The relative density of the two kinds of soil samples was 2.71 , indicating that the influence of grain composition on relative density of soil grain was very small and all kinds of clay content of gravel soil can use the same value (2.71). The relative density of the soil sample of clay content of $10 \%$ was measured by a jar and the soil sample of clay content of $45 \%$ was measured by a pycnometer.

2.3. Experiment Principle. The frost heave amount and frostheaving ratio are the main parameters to measure the frost heave properties of soil. The frost heave amount is the vertical displacement of the soil which is caused by soil

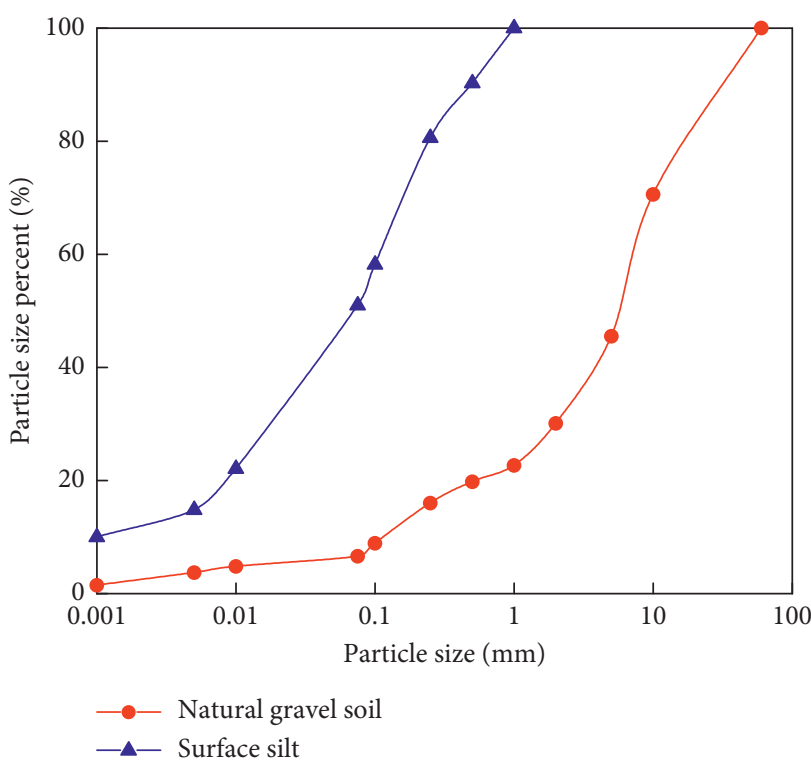

FIgURE 1: Gradation curve.

TABLE 1: Results of standard compaction test.

\begin{tabular}{lcc}
\hline Clay content (\%) & $\begin{array}{c}\text { Standard maximum } \\
\text { dry density }\left(\mathrm{g} / \mathrm{cm}^{3}\right)\end{array}$ & $\begin{array}{c}\text { The optimum initial } \\
\text { moisture content }(\%)\end{array}$ \\
\hline 10 & 2.36 & 6.69 \\
15 & 2.33 & 7.00 \\
20 & 2.29 & 7.66 \\
25 & 2.25 & 8.27 \\
45 & 2 & 13.02 \\
\hline
\end{tabular}

freezing. While the later (also known as the frost heave coefficient) is the ratio of the increment of the longitudinal height to the original height of the specimen under the condition of nonlateral deformation and one-dimensional freeze. The frost-heaving ratio is usually expressed as follows:

$$
\eta=\frac{\Delta h}{H_{\mathrm{f}}} \times 100 \%
$$

where $\eta$ is the frost-heaving ratio, $\Delta h$ is the frost heave amount at the end of the freeze $(\mathrm{mm})$, and $H_{\mathrm{f}}$ is the frozen depth $(\mathrm{cm})$ (Test Methods of Soils for Highway Engineering).

The frozen depth can be determined with Equation (2).

$$
H_{x}=H\left(i+\frac{\left|t_{i}^{-}\right|}{\left|t_{i}^{-}\right|+t_{i+1}^{+}}\right)
$$

where $H_{x}$ is the frozen depth, $H$ is the spacing of temperature measuring element $(H=2.0 \mathrm{~cm}), i$ is the layer number of temperature measuring element from the surface to calculate, $\left|t_{i}^{-}\right|$is the absolute value of negative temperature of level $i$, and $t_{i+1}^{+}$is the absolute value of positive temperature of level $i+1$, and the calculating diagram is indicated in Figure 2.

2.4. Experiment Apparatus Improvement. According to Test Methods of Soils for Highway Engineering JTG E402007 [40], the traditional frost heave experiment apparatus 


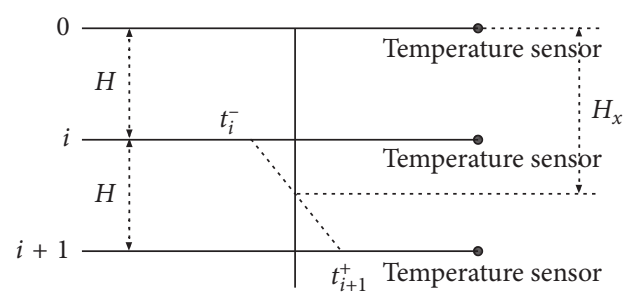

FIgURE 2: Schematic diagram of frozen depth calculation.

consists of a soil sample box, a pressure system, a water replenishing system, a displacement monitoring system, a temperature control system, and a calorstat. The schematic diagram of traditional frost heave experiment apparatus is shown in Figure 3.

However, due to the small size of the apparatus, the standard rule is only applicable to the small size soil such as cohesive soil and sandy soil, but not suitable for the determination of the frost-heaving ratio of the gravel soil with larger particle size. In addition, the traditional frost-heaving ratio experiment apparatus also has some defects; therefore, the following improvements have been made. (1) Size of the soil sample box was increased. According to the principle of similarity, the inside diameter was increased from $10 \mathrm{~cm}$ to $15 \mathrm{~cm}$, the height was increased from $10 \mathrm{~cm}$ to $16 \mathrm{~cm}$, and the spacing of temperature sensors was increased from $1 \mathrm{~cm}$ to $2 \mathrm{~cm}$. (2) A modified pressure system was used in the experiment. The weight pressure was replaced with air cylinder pressure, and the range of pressure was increased to make the adjustment more convenient. The new pressure system consists of an air compressor, pressure regulating valves, an air cylinder, and a connecting pipe. (3) Data acquisition system has been improved. The dial indicator with an accuracy of $0.05 \mathrm{~mm}$ was replaced by a displacement sensor with an accuracy of $0.001 \mathrm{~mm}$ for observing the changes in the frost heave amount. All sensors could collect the signals of displacement and temperature automatically, and the signals were recorded and saved automatically by computer. (4) Cold bath system has been improved. In the traditional frost-heaving ratio experiment apparatus, the cold bath system only set a fixed freezing temperature, which was inconsistent with the actual law of atmospheric cooling. Therefore, a cold bath system with automatic cooling function was adopted to make the freezing temperature more in line with the actual situation. In addition, the cold side was set at the bottom in the traditional frost-heaving ratio experiment apparatus, which does not match the actual of top-down cooling of the foundation. In the improved frost-heaving ratio experiment apparatus, the cold side was set at the top in line with the actual situation. (5) Water replenishing system has been improved. The Maddox water replenishing bottle was used to keep water level constant, and the water import was charged from top to bottom for adapting the actual groundwater replenishing. The displacement sensor collecting and saving data automatically was used to observe change of the water level in the water replenishing system. After the improvement, the new frost heave experiment apparatus consists of soil a sample box, constant temperature environment of box and temperature

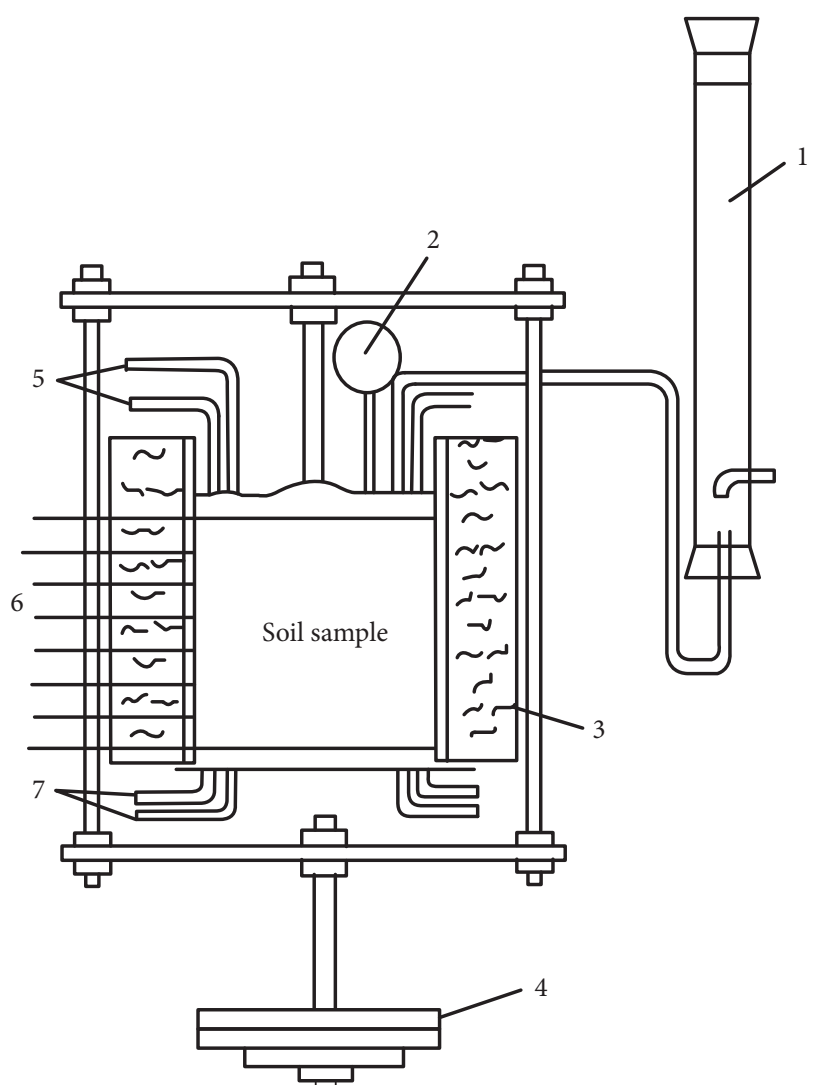

FIgURE 3: Traditional frost heave experiment apparatus. (1) Water replenishing apparatus. (2) Dial indicator of heave. (3) Thermal insulation material. (4) Pressure apparatus. (5) Positive temperature circulative liquid import and export. (6) Thermistor temperature measuring point. (7) Negative temperature circulative liquid import and export.

control system, the temperature monitoring system, displacement acquisition unit monitoring system, data acquisition unit, pressure system, and water replenishing system, just as shown in Figures 4 and 5.

The temperature sensor, displacement sensor, and data acquisition terminal used in the experiment were all highprecision equipment. All the experiment units had been calibrated before the experiment began, which ensured the accuracy of the experimental results. At the same time, the upper and lower sides of the cylinder wall were tightened in order to reduce the error caused by deformation of the sample cylinder itself. The soil sample box was surrounded by thermal insulation material for preventing temperature loss. Two filter papers were put on top and bottom of the soil sample in order to prevent moisture loss during the experiment. Moreover, in order to verify the reliability of the improved frost heave experiment apparatus, several groups of tests were carried out in comparison with the traditional frost heave experiment apparatus.

Specifically, the laboratory tests on one-dimensional frost heave were carried out by the traditional experiment apparatus and the improved experiment apparatus, respectively, under the conditions of the same soil sample (clay content $45 \%$ ), the same test factor index (compactness $95 \%$, 


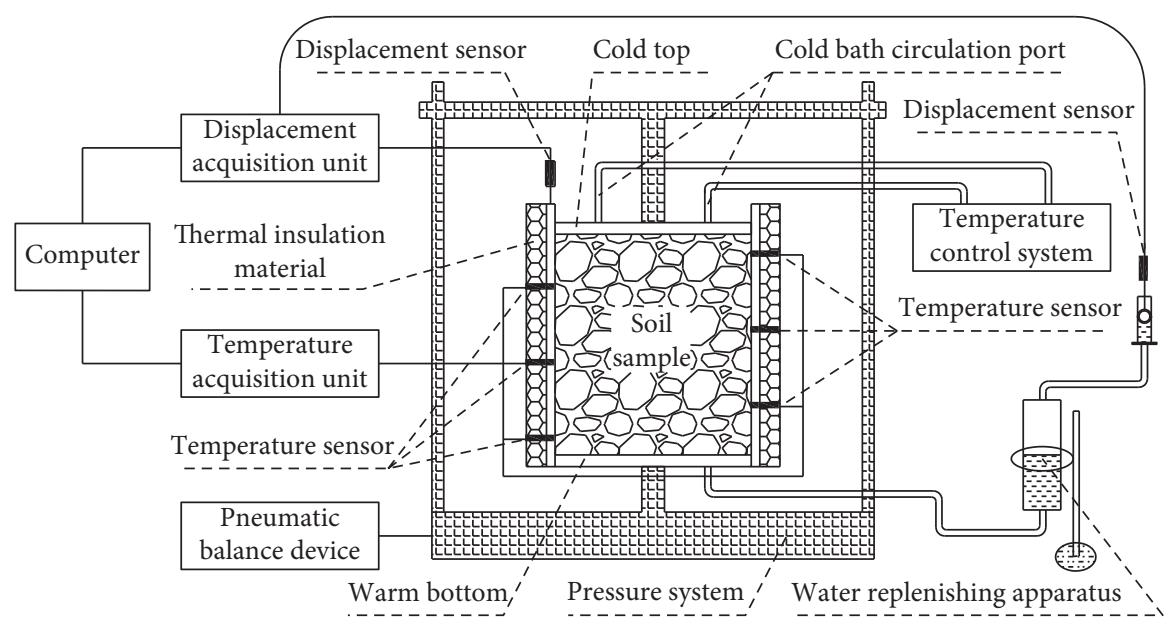

FIGURE 4: Schematic diagram of the improved frost heave experiment apparatus.
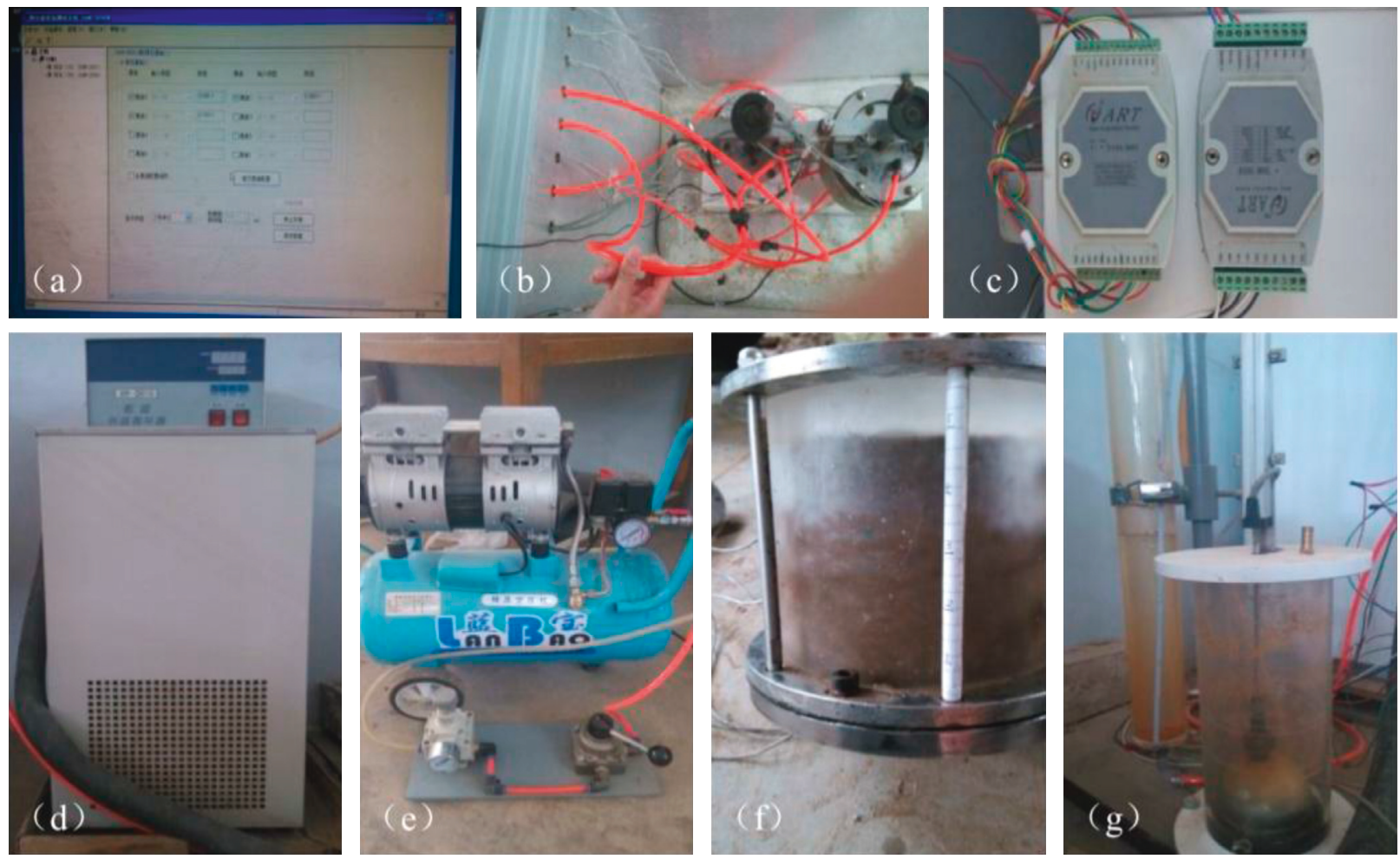

Figure 5: Improved frost heave experiment apparatus. (a) Altai measurement and control system. (b) Thermostat. (c) Data acquisition unit. (d) Cryostat. (e) Pneumatic balance apparatus. (f) Soil sample box. (g) Maddox water replenishing bottle.

overlying load $20 \mathrm{kPa}$ ), and the same cooling environment. The results of the contrast tests are shown in Figure 6. It could be seen that the results of the two groups of test results almost coincide, verifying the reliability of the improved frost heave experiment apparatus. Therefore, the improved frost heave experiment apparatus could be used to test the frost-heaving ratio of coarse-grained soils.

2.5. Experiment Program and Procedures. The initial water content, clay content, compactness, and overlying load were selected as 4 factors, and the multifactor experimental design was carried out. The initial moisture content was designed according to the optimum initial moisture content to the above 5 kinds of soil clay content in the size of the $3 \%-18 \%$ corresponding to the 3-5 levels. Considering that the compactness of the actual airport foundation was generally controlled at around 90\%-98\%, we chose $85 \%, 90 \%$, $95 \%$, and $100 \%$ as compaction indexes. The overlying load was selected as 4 levels, such as $10 \mathrm{kPa}, 20 \mathrm{kPa}, 30 \mathrm{kPa}$, and $40 \mathrm{kPa}$. In order to explore the order of influence of various factors on frost-heaving ratio and to obtain the multifactor regression empirical formula for predicting the frostheaving ratio of gravel soil under certain collocation of 


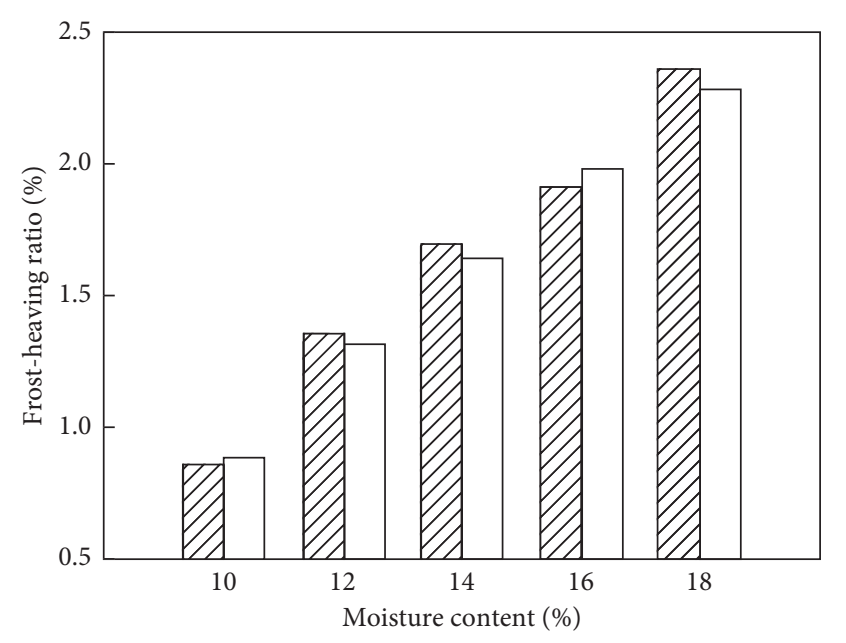

VIZ Traditional experiment apparatus Improved experiment apparatus

Figure 6: The contrast test between improved experiment apparatus and traditional experiment apparatus.

factors and levels, the multifactor analysis was conducted on the basis of single factor test results.

The temperature of cold bath and the calorstat was set to $1^{\circ} \mathrm{C}$ for $6 \mathrm{~h}$ to ensure that the internal temperature of the sample reached $1^{\circ} \mathrm{C}$, at which point the freezing process was initiated. During the freezing process, the temperature of the cold bath declined from $1^{\circ} \mathrm{C}$ at the speed of $0.2^{\circ} \mathrm{C} / \mathrm{h}$, lasting approximately $72 \mathrm{~h}$ until stability of deformation, to simulate the law of atmospheric cooling [41]. After the freezing, the sample was removed immediately from the soil sample box, and then equally divided into 7 pieces by slices. Moisture distribution in the sample was measured by drying method.

\section{Results and Analysis}

\subsection{Influence of Various Factors on Frost-Heaving Ratio}

3.1.1. Initial Moisture Content. The influence of various initial moisture contents on frost-heaving ratio is shown in Table 2. Frost-heaving ratio increases with initial moisture content when clay content remains unchanged. The reason is considered as follows: the increase of moisture content makes the water bonding in the soil sample more tight, and the continuous movement of water is more obvious. As we can see from the fitting curves, frost-heaving ratio and initial moisture content indicated unary linear relation. The size order of slope of fitting curve is $25 \%>45 \%>15 \%$. This may be attributed to that the dry density of the soil sample of clay content $45 \%$ was the least among the three (refer to the results of standard compaction test). The more loose the soil structure is, the bigger the soil pore is, the more the ice accommodates, and the less the frost-heaving ratio is. The dry density of the soil sample of clay content $25 \%$ is bigger than the one of clay content $45 \%$, and the moisture migration was more obvious because of the less soil pore. The dry density and the cohesive force between soil particles of soil samples with clay content of $15 \%$ are all the largest among the three. Therefore, it is the most likely to produce overlapping and thickening combined water film, which makes the permeability of soil decrease and the channel of water migration narrow.

3.1.2. Clay Content. The influence of various clay contents on frost-heaving ratio is shown in Table 3. As we can see from the fitting curves, the frost-heaving ratio increases with clay content corresponding to a polynomial function when degree of saturation remains unchanged. The reason is considered as follows: the increase of clay content leads to the increase of total surface area and surface energy of soil particles, and more surface energy makes the soil particles absorb more water film. The water film between soil particles is interconnected to form a thin film channel conducive to continuous moisture migration. As the clay content is fixed, the frost-heaving ratio increases with the increase of saturation. The reason is considered as follows: besides the reason that the initial moisture content increases with the increase of the saturation, the volume of the soil pore decreases with the increase of the saturation, and the pore is more easily filled with frozen ice, which is more likely to cause the frost heave displacement of the soil particles. Comparing the coefficients of the three fitting curves in Table 3, it is known that the frostheaving ratio and the clay content are nonlinear increasing relation, and the growth rate decreases gradually. When the clay content is small, the frost-heaving ratio increases rapidly. When the clay content is large, the growth rate of frostheaving ratio gradually slows down.

3.1.3. Compactness. The influence of various compactness on frost-heaving ratio is shown in Table 4. Frost-heaving ratio increased first and then decreased with the increase of compactness in the form of polynomial function and approached its maximum at the compactness of $95 \%$, when overlying load, initial moisture content, and clay content remain unchanged. When the compactness is less than $95 \%$, the film continuity of nonfrozen moisture increases with the compactness, which contributes to moisture migration and freezing and lead to the increase of frost heave intension. When the compactness reaches to some critical value where thin film channel is least, frost heave intension approaches its maximum. However, with the increase of compactness, the frost-heaving strength of soil decreases. This is due to the reduction of pore volume in soil and the increase of effective contact area between soil particles, resulting in the superposition of the water film on the periphery and the obstruction of moisture migration during freezing.

3.1.4. Overlying Load. The influence of various initial moisture contents on frost-heaving ratio is shown in Table 5 . Frost-heaving ratio decreases with overlying load, which indicates that the overlying load has inhibitory effect on frost-heaving ratio. Through the three fitting curves in Table 5 , it is found that the frost-heaving ratio gently decreased linearly with the increase of overlying load. 
TABLE 2: Influence of various initial moisture contents on frost-heaving ratio.

\begin{tabular}{|c|c|c|c|c|c|c|c|}
\hline Test no. & $\begin{array}{c}\text { Compactness } \\
(\%)\end{array}$ & $\begin{array}{l}\text { Overlying } \\
\text { load (kPa) }\end{array}$ & $\begin{array}{c}\text { Clay } \\
\text { content }(\%)\end{array}$ & $\begin{array}{l}\text { Initial moisture } \\
\text { content }(\%)\end{array}$ & $\begin{array}{l}\text { Frost-heaving } \\
\text { ratio }(\%)\end{array}$ & Fitting curve & $R^{2}$ \\
\hline 1 & \multirow{13}{*}{95} & \multirow{13}{*}{20} & \multirow{4}{*}{15} & 3 & 0.43 & \multirow{4}{*}{$y=0.093 x+0.137$} & \multirow{4}{*}{0.952} \\
\hline 2 & & & & 5 & 0.62 & & \\
\hline 3 & & & & 7 & 0.71 & & \\
\hline 4 & & & & 9 & 1.02 & & \\
\hline 5 & & & \multirow{4}{*}{25} & 6.43 & 0.81 & \multirow{4}{*}{$y=0.244 x-0.767$} & \multirow{4}{*}{0.991} \\
\hline 6 & & & & 7.35 & 0.99 & & \\
\hline 7 & & & & 8.27 & 1.28 & & \\
\hline 8 & & & & 9.19 & 1.46 & & \\
\hline 9 & & & \multirow{5}{*}{45} & 10 & 0.88 & \multirow{5}{*}{$y=0.173 x-0.802$} & \multirow{5}{*}{0.995} \\
\hline 10 & & & & 12 & 1.32 & & \\
\hline 11 & & & & 14 & 1.64 & & \\
\hline 12 & & & & 16 & 1.98 & & \\
\hline 13 & & & & 18 & 2.28 & & \\
\hline
\end{tabular}

TABLE 3: Influence of various clay contents on frost-heaving ratio.

\begin{tabular}{|c|c|c|c|c|c|c|c|}
\hline Test no. & $\begin{array}{c}\text { Compactness } \\
(\%)\end{array}$ & $\begin{array}{l}\text { Overlying } \\
\text { load }(\mathrm{kPa})\end{array}$ & Saturation & $\begin{array}{c}\text { Clay } \\
\text { content }(\%)\end{array}$ & $\begin{array}{l}\text { Frost-heaving } \\
\text { ratio }(\%)\end{array}$ & Fitting curve & $R^{2}$ \\
\hline 1 & \multirow{12}{*}{95} & \multirow{12}{*}{20} & \multirow{4}{*}{0.8} & 10 & 0.10 & \multirow{4}{*}{$y=-0.0012 x^{2}+0.1012 x-0.791$} & \multirow{4}{*}{1} \\
\hline 2 & & & & 15 & 0.46 & & \\
\hline 3 & & & & 20 & 0.75 & & \\
\hline 4 & & & & 25 & 0.99 & & \\
\hline 5 & & & \multirow{4}{*}{0.9} & 10 & 0.19 & \multirow{4}{*}{$y=-0.0025 x^{2}+0.1589 x-1.1395$} & \multirow{4}{*}{0.9972} \\
\hline 6 & & & & 15 & 0.71 & & \\
\hline 7 & & & & 20 & 1.01 & & \\
\hline 8 & & & & 25 & 1.28 & & \\
\hline 9 & & & & 10 & 0.28 & \multirow{4}{*}{$y=-0.0042 x^{2}+0.2258 x-1.559$} & \multirow{4}{*}{1} \\
\hline 10 & & & & 15 & 0.88 & & \\
\hline 11 & & & 1 & 20 & 1.28 & & \\
\hline 12 & & & & 25 & 1.46 & & \\
\hline
\end{tabular}

TABLE 4: Influence of various compactness on frost-heaving ratio.

\begin{tabular}{|c|c|c|c|c|c|c|c|}
\hline Test no. & $\begin{array}{l}\text { Overlying } \\
\text { load }(\mathrm{kPa})\end{array}$ & $\begin{array}{l}\text { Initial moisture } \\
\text { content }(\%)\end{array}$ & $\begin{array}{c}\text { Clay } \\
\text { content }(\%) \\
\end{array}$ & $\begin{array}{c}\text { Compactness } \\
(\%)\end{array}$ & $\begin{array}{l}\text { Frost-heaving } \\
\text { ratio }(\%)\end{array}$ & Fitting curve & $R^{2}$ \\
\hline 1 & \multirow{12}{*}{20} & \multirow{5}{*}{7} & \multirow{4}{*}{15} & 85 & 0.51 & \multirow{4}{*}{$y=-0.0022 x^{2}+0.4158 x-18.939$} & \multirow{4}{*}{0.9991} \\
\hline 2 & & & & 90 & 0.66 & & \\
\hline 3 & & & & 95 & 0.71 & & \\
\hline 4 & & & & 100 & 0.64 & & \\
\hline 5 & & & \multirow{4}{*}{25} & 85 & 0.98 & \multirow{4}{*}{$y=-0.0031 x^{2}+0.5869 x-26.515$} & \multirow{4}{*}{0.9871} \\
\hline 6 & & \multirow{3}{*}{8.27} & & 90 & 1.18 & & \\
\hline 7 & & & & 95 & 1.28 & & \\
\hline 8 & & & & 100 & 1.17 & & \\
\hline 9 & & \multirow{4}{*}{18} & \multirow{4}{*}{45} & 85 & 2.08 & \multirow{4}{*}{$y=-0.0023 x^{2}+0.4329 x-18.105$} & \multirow{4}{*}{0.9707} \\
\hline 10 & & & & 90 & 2.21 & & \\
\hline 11 & & & & 95 & 2.28 & & \\
\hline 12 & & & & 100 & 2.18 & & \\
\hline
\end{tabular}

3.1.5. Water Replenishing. The relationship between the frost-heaving ratio and water replenishing is shown in Figure 7. In contrast to the closed and open water replenishing condition, the frost-heaving ratio in the open water replenishing condition could be found to increase several times more than that of the closed water replenishing condition. This may be attributed to that the pore pressure which is formed by moisture migration drive replenishing water to the freeze frontal surface, then grow ice lens, caused the sharp increase of frost-heaving ratio. It is fully indicated that the external water replenishing is the main factor causing the frost heave of gravel soil foundation. In the prevention and control of frost heave measures, preventing water replenishing is more important than other factors. 
TABLE 5: Influence of various overlying load on frost-heaving ratio.

\begin{tabular}{|c|c|c|c|c|c|c|c|}
\hline Test no. & $\begin{array}{c}\text { Compactness } \\
(\%)\end{array}$ & $\begin{array}{c}\text { Initial moisture } \\
\text { content }(\%)\end{array}$ & $\begin{array}{c}\text { Clay } \\
\text { content (\%) }\end{array}$ & $\begin{array}{l}\text { Overlying } \\
\text { load (kPa) }\end{array}$ & $\begin{array}{l}\text { Frost-heaving } \\
\text { ratio }(\%)\end{array}$ & Fitting curve & $R^{2}$ \\
\hline 1 & \multirow{12}{*}{95} & \multirow{4}{*}{6.69} & \multirow{4}{*}{10} & 10 & 0.22 & \multirow{4}{*}{$y=-0.0021 x+0.235$} & \multirow{4}{*}{0.8909} \\
\hline 2 & & & & 20 & 0.19 & & \\
\hline 3 & & & & 30 & 0.16 & & \\
\hline 4 & & & & 40 & 0.16 & & \\
\hline 5 & & \multirow{4}{*}{7} & \multirow{4}{*}{15} & 10 & 0.76 & \multirow{4}{*}{$y=-0.0022 x+0.775$} & \multirow{4}{*}{0.7118} \\
\hline 6 & & & & 20 & 0.71 & & \\
\hline 7 & & & & 30 & 0.73 & & \\
\hline 8 & & & & 40 & 0.68 & & \\
\hline 9 & & \multirow{4}{*}{7.66} & \multirow{4}{*}{20} & 10 & 1.07 & \multirow{4}{*}{$y=-0.0034 x+1.095$} & \multirow{4}{*}{0.9323} \\
\hline 10 & & & & 20 & 1.01 & & \\
\hline 11 & & & & 30 & 1 & & \\
\hline 12 & & & & 40 & 0.96 & & \\
\hline
\end{tabular}

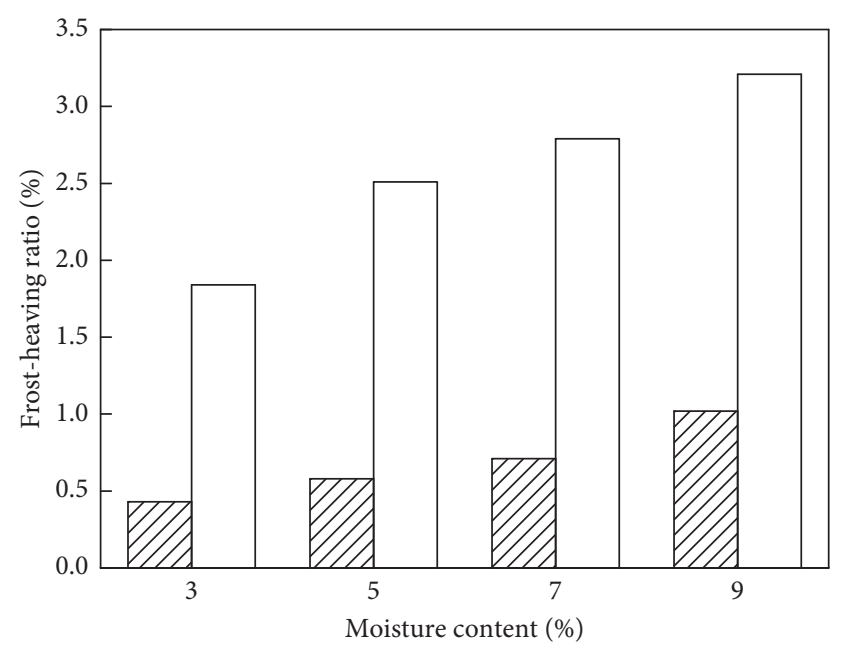

VIA Closed

Open

Figure 7: Relationship between water replenishing and frostheaving ratio.

\subsection{The Basic Characteristics of Typical Frost Heave Process}

3.2.1. Frost Heave Amount and Frost Heave Speed. In order to gain a deep insight into the basic laws of typical process of the frost heave of gravel soil, we selected a set of typical frost heave processes from all the experimental results. In our experiment, the sample (initial moisture content 9\%, silt content $15 \%$, and compactness $95 \%$, overlying load $20 \mathrm{kPa}$ ) was chosen as a group of typical specimens. The variation of frost heave amount with time is shown in Figure 8, and the relationship between frost heave speed and time during the freezing is shown in Figure 9.

From the process of frost heave of gravel soil, it can be seen that there are approximately four phases. (i) The frozenshrink phase: the frost heave amount and the frost heave speed were very small and developed slowly, even showed as negative value. The frost heave amount not only did not increase, but decreased due to the shrinkage of soil particle at low temperature. (ii) The fast-increasing phase: as freezing time continues, the frost heave amount increased rapidly.

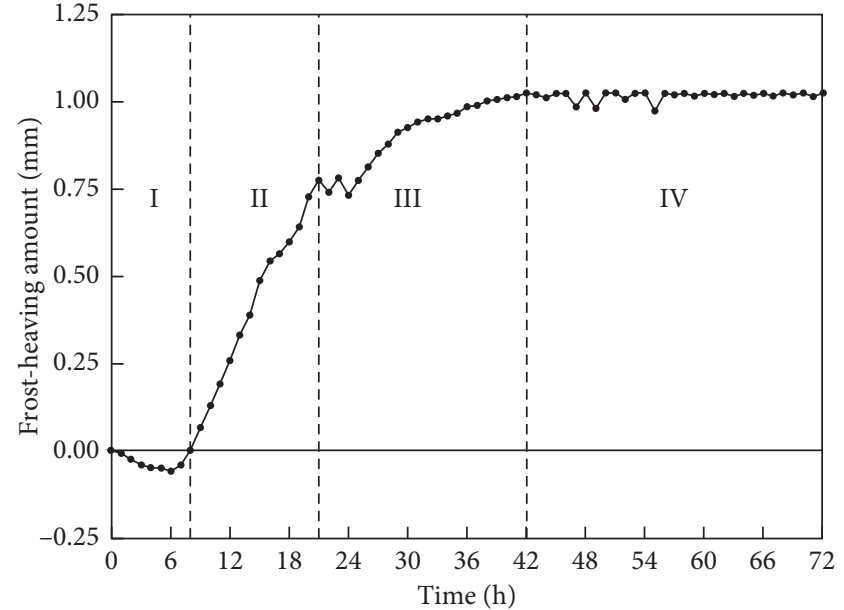

FIgURE 8: Variation of frost heave amount with time.

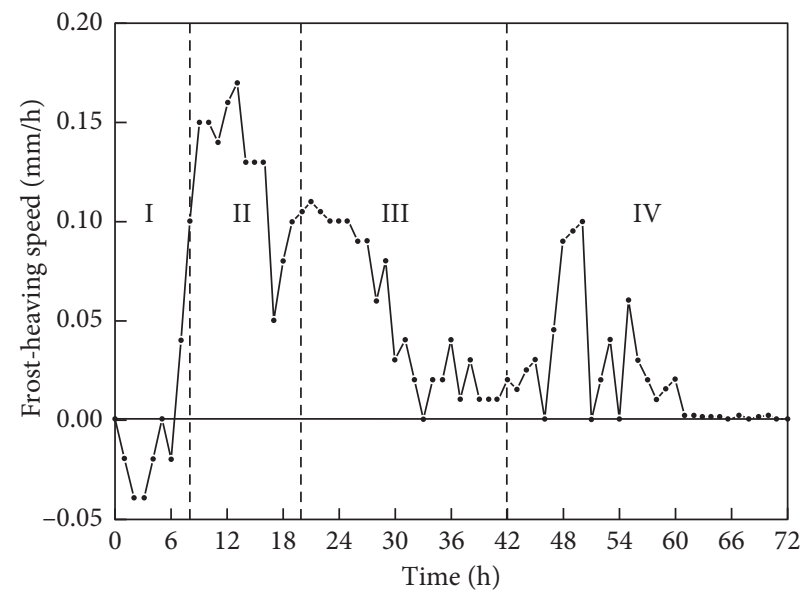

FIgURE 9: Variation of frost heave speed with time.

The frost heave speed rose rapidly and reached the peak due to the intense ice segregation during this period, indicating that soil frost heave deformation rapidly increased. (iii) The slow-increasing phase: over time, the frost heave speed gradually decreased and frost heave amount increased 
slowly. This may be attributed to that the migration of moisture to the ice lens would decrease due to insufficient moisture supply under the closed water replenishing condition as well as the low permeability of the frozen fringe [34]. The slow growth of the thickness of ice lens and degree of succession lead to the decrease of growth speed of frost heave amount. (iv) The relatively stable phase: during this phase, the frost heave speed reached 0 and lasted to the end of the experiments. Although there were fluctuations which may be caused by unstable voltage, the frost heave speed varied within quite narrow limits than those in phases (2) and (3) [42]. The amount of unfrozen moisture decreased, resulting in decreasing in moisture migration and stopping growing of ice lens. The moisture migration is primarily driven by the difference in soil moisture potential around the frost front under a closed water replenishing condition [34]. Correspondingly, frost heave amount decreased eventually reaching a near constant value.

3.2.2. Frozen Depth and Freezing Speed. The relationship between frozen depth and time during the freezing is shown in Figure 10. The frozen depth was observed to gradually shift downward from the top of the sample (initial moisture content $9 \%$, clay content $15 \%$, and compactness $95 \%$ and overlying load $20 \mathrm{kPa}$ ) at the beginning of the freezing process when cooling was applied. As freezing time continues, the variation gradient of frozen depth becomes smaller and smaller. After a certain period of time, the soil sample reached a stabilization phase with small change in frozen depth. The rate of frost front advance and maximum frozen depth were found to be dependent on initial moisture content, thermal conductivity, and cooling temperature [43].

The relationship between freezing speed and time during the freezing is shown in Figure 11. The freezing speed was significantly greater during the phases (1) and (2) than those in phases (3) and (4). As freezing time continues, the freezing speed gradually decreases. It is believed that the freezing speed is one of main factors affecting the development of frost heave [42]. Comparing Figures 8 and 11, the freezing speed in phase (1), where the frost heave speed was negative, was less than that in phase (2) due to frozen-shrink phenomenon. The frost heave increased rapidly due to the larger frost heave speed and freezing speed in phase (2). As the frost heave speed and freezing speed keep decreasing, the rate of development of frost heave slowed down in phase (3) and reached the minimum until the last phase. It was observed that the tendency of the changes of frost heave speed and freezing speed was similar; this is consistent with the conclusion of Zhou et al. [18].

3.2.3. Moisture Content Distribution in Soil after Freezing. After freezing for different durations, we cut the soil sample by slice and then measure the moisture content of slice by drying method. The relationship between the moisture content distribution and time after freezing is shown in Figure 12 for the same sample. It was assumed that initial moisture content in the sample is uniformly distributed (the curve of $9 \%$ in Figure 12). The depth of 0 in Figure 10

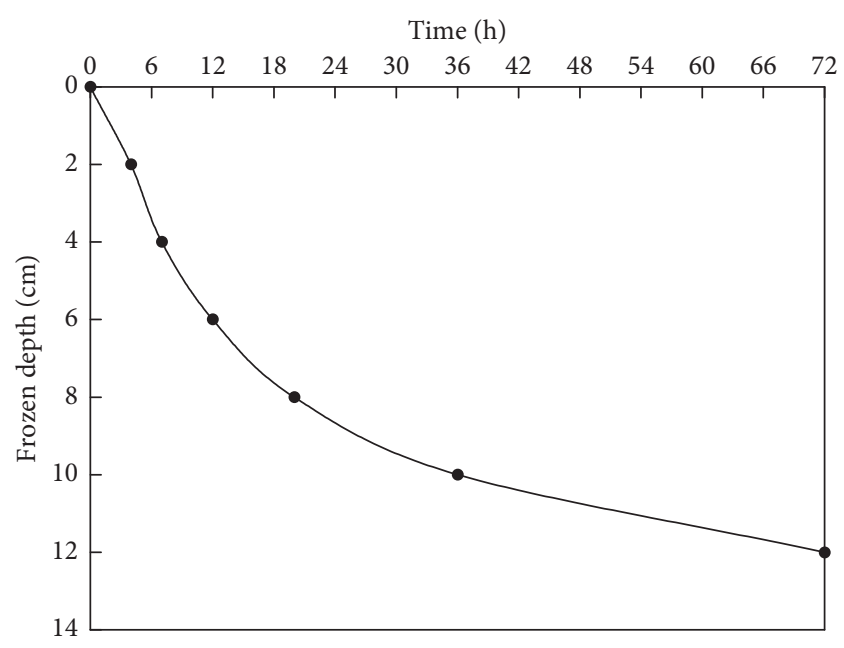

Figure 10: Variation of frozen depth with time.

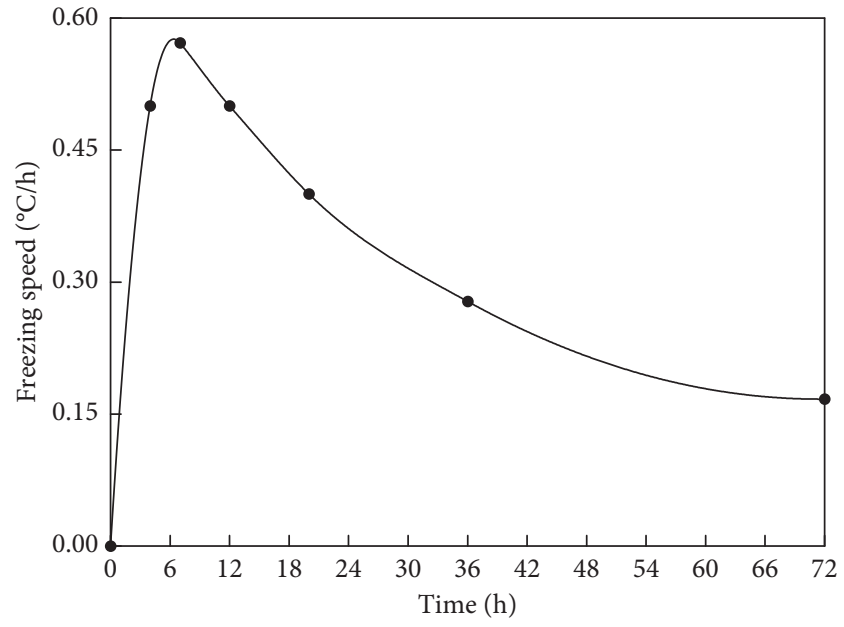

FIGURE 11: Variation of freezing speed with time.

indicates the cold side, while the depth of $14 \mathrm{~cm}$ indicates the warm side. The moisture content on the cold side was significantly larger than that on the warm side, which indicated that moisture migration during freezing occurred in the gravel soil sample. The moisture content in the frozen section was also considerably greater than initial moisture content. Conversely, the moisture content in the nonfrozen section was significantly lower than the initial moisture content. The moisture distribution after different freezing times ( $4 \mathrm{~h}, 12 \mathrm{~h}, 36 \mathrm{~h}$, and $72 \mathrm{~h}$ ) was found to be similar in trend and follow an S-shape. The different frozen depths $(2 \mathrm{~cm}, 6 \mathrm{~cm}, 10 \mathrm{~cm}$, and $12 \mathrm{~cm})$ after corresponding freezing times $((4 \mathrm{~h}, 12 \mathrm{~h}, 36 \mathrm{~h}$, and $72 \mathrm{~h})$ (refer to Figure 10$))$, which served as the dividing line between the frozen section and the nonfrozen section, distinguished between an increase and a decrease in moisture content. The moisture content increment at the cold side and the maximum frozen depth were observed to be greater compared with other positions in the sample. This may be attributed to the larger porosity of the gravel soil, and the soil moisture potential produced by the temperature gradient resulted in a migration of moisture 


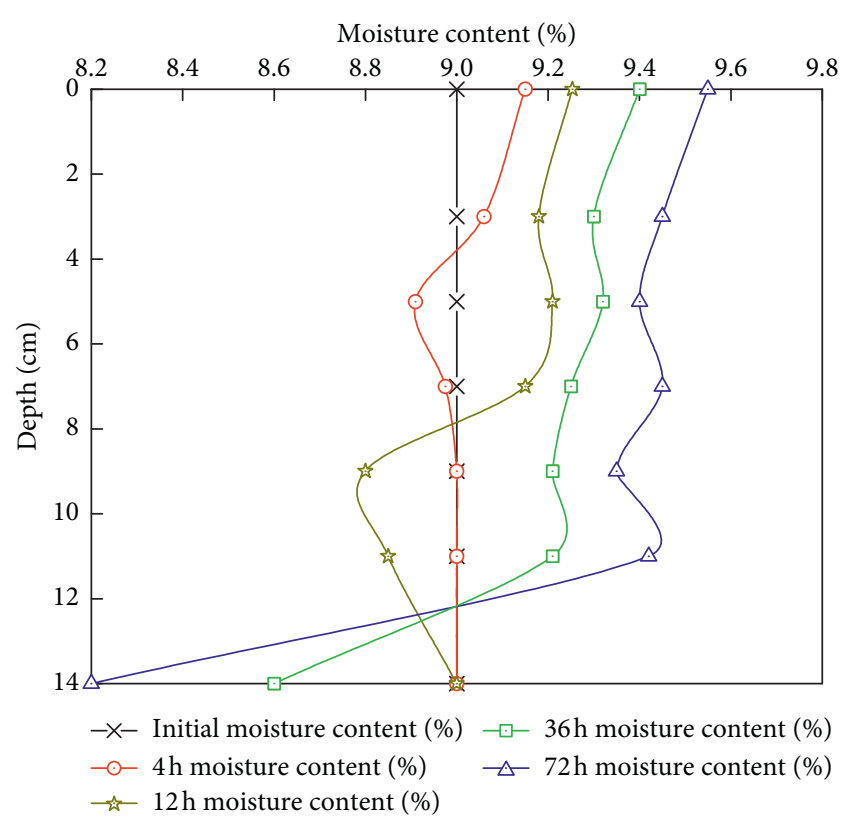

FIGURE 12: Moisture content distribution in soil after freezing of different duration.

near the frost front to the ice lens at the beginning of freezing. Over time, an increase in the frozen depth and reduction in moisture near the frost front were observed and led to a decrease in the permeability of the frozen front and a reduction in moisture migration. The moisture moved upward to the frost front due to the reduced moisture migration near the warm side at the beginning of freezing, resulting in a greater increment in moisture content around the maximum frozen depth [34]. The moisture increment between the cold side and warm side was small due to minimal moisture migration in gravel soil under a closed water replenishing condition. Over time, the moisture content near the freezing front increased markedly, whereas the moisture content in the frozen zone away from the freezing front varied slightly.

3.3. Multifactor Regression Analysis. The multifactor regression equation was built with initial moisture content, clay content, compactness, and overlying load as independent variables and with frost-heaving ratio as dependent variable based on MATLAB.

$$
\begin{aligned}
\eta= & 0.14765 \omega_{m}+0.12152 \omega_{s}-0.00208 \omega_{s}^{2}-0.04818 K \\
& +0.00032 K^{2}-0.00274 P .
\end{aligned}
$$

Correctional goodness of fit $R^{2}=0.99, F$-test $F=$ $542.76>F_{0.05}(4,36)=2.65$, the infective of the regression equation together with the regression coefficient were distinctness by significance testing. The fitting accuracy is high. This suggested that under the closed water replenishing condition, the importance order of the factors is initial moisture content $>$ clay content $>$ compactness $>$ overlying load. The application range of regression prediction formula is initial moisture content $(3 \%, 18 \%)$, clay content $(10 \%, 45 \%)$, compactness $(85 \%, 100 \%)$, and overburden load $(10 \mathrm{kPa}$, $40 \mathrm{kPa}$ ). Fitting values were obtained through the multifactor regression equation and then compared with fitting values as indicated in Figure 13. It is known from Figure 13 that the fitting degree of formula (3) is high, indicating that the model has a high accuracy and a certain validity. The application of this regression model can predict the frostheaving ratio under the comprehensive influence of different factors and has a certain application value in the design of antifrost heave in building engineering.

\section{Discussion}

The frost-heaving ratio of gravel soil increases linearly with the increase of water content, which has been confirmed by many researches [44]. The frost-heaving ratio of $1 \%$ is considered as a criterion for determining the frost heave sensitivity of coarse-grained soil [27, 28]. Coarse-grained soil with clay content less than $15 \%$ is generally considered to be a frost heave insensitive soil. When the clay content is over 15\%, the frost heave of coarse-grained soils is more obvious [30]. The experiment results in this paper are consistent with these conclusions. When the clay content is $15 \%$, even though the optimal moisture content is 7\% (Table 1), the frost-heaving ratio of gravel soil is still less than $1 \%$. When the clay content is $10 \%$, the frost-heaving ratio is not more than $0.3 \%$, even when the saturation is 1 . When the clay content is $25 \%$, the frost-heaving ratio of gravel soil is almost $1 \%$. Therefore, it can be believed that gravel soil with less than $15 \%$ of clay content is a frost heave insensitive soil. It is suggested that $15 \%$ of the clay content should be used as the control standard of the gravel soil frost-heaving ratio in the actual project.

According to the research of $\mathrm{Xu}$ [25]; the content of powder clay in granular soil is less than $12 \%$ and the frostheaving ratio is not more than $2 \%$ even under sufficient water saturation. As the content of powder clay is greater than $12 \%$, the frost-heaving ratio increases obviously. It is shown in Table 3 that the frost-heaving ratio is not more than $0.3 \%$, even when the saturation is 1 , with the clay content of $10 \%$. When the clay content is more than $15 \%$, even under unsaturated conditions, the frost-heaving ratio is still more than $0.5 \%$. This fully reflects the significant effect of the clay content on the frost-heaving ratio and validates the applicability of the control standard of $15 \%$ clay content.

Chen et al. [20] show that in an open water replenishing condition, the frost-heaving ratio of sand gravel increases exponentially with the increase of the content of fine grain soil. Under the closed water replenishing condition of this research, the frost-heaving ratio of gravel soil increases with the increase of clay content in a nonlinear increasing relation (Table 3). In addition to the reasons for water replenishment, the general trend of the two is consistent except for the different rate of growth and change. Under the open water replenishing condition, the frost-heaving ratio is easy to replenish more moisture when the clay content is large, resulting in a significant increase in the frost-heaving ratio. Under the closed water replenishing condition, the growth rate of frost-heaving ratio decreases with the limited water content. 


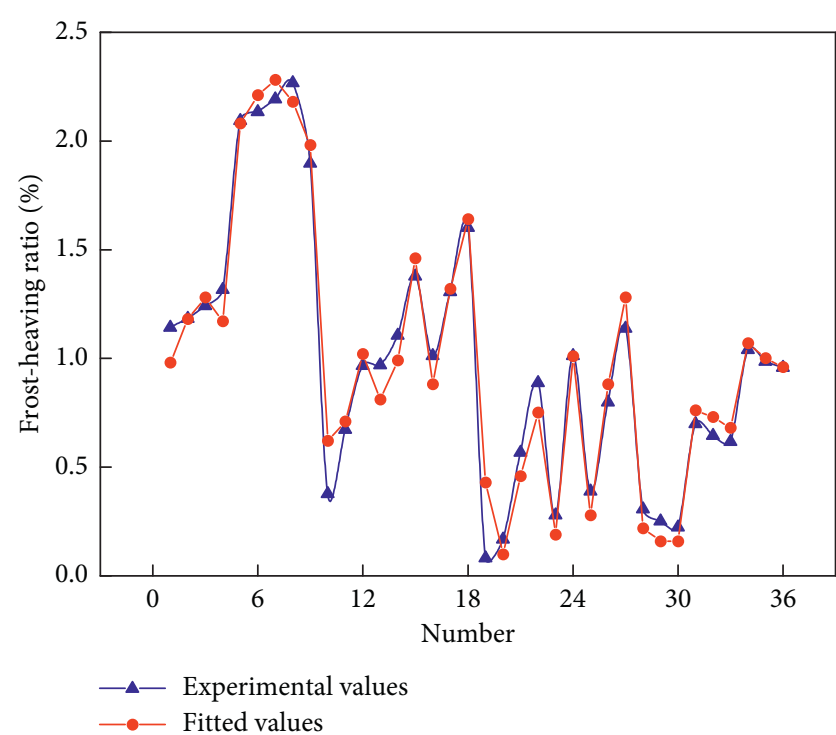

Figure 13: Contrast of experimental and fitting values of frostheaving ratio.

The results of this paper show that $95 \%$ of compaction is the maximum threshold of gravel soil frost-heaving ratio, which is similar to the results obtained from the related research results [45]. In airport pavement foundation construction, the compaction is generally controlled within the range of $95 \%$ $98 \%$. Based on the $95 \%$ threshold obtained from the experimental results, we propose to increase the construction compactness to $98 \%$, so as to reduce the frostheaving ratio.

The research results of Li and Zhu [44] and Bao et al. [46] confirmed the suppressing effect of overlying load on frost heave. Bao et al. [46] thinks that the inhibition is related to water migration caused by consolidation and drainage and freezing. In this experiment, the overlying load leads to the consolidation and drainage trend from the top to the bottom of the soil. The cold side on the top causes the moisture migration trend from the bottom to the top of the soil. The two effects cancel each other, which results in the inhibition of the overburden load on the frostheaving ratio. By curve fitting of the data of the three groups, it can be found that the frost-heaving ratio decreases with overlying load in a negative exponential form. By investigating the slope of fitting curve of frost-heaving ratio and overlying load variation (Table 5), we find that with the increase of overlying load, the decrease of frostheaving ratio is relatively small, indicating that this inhibition effect is smaller. This may be attributed to that the external load is much less than the huge frost-heaving force generated by the frost heaving inside the soil, so the restraining effect of the overlying load on frost-heaving ratio is very small.

It is documented that the basic process of frost heave of fine-grained soils was also divided into four phases [42]. However, because of the different physical characteristics of coarse-grained soil and fine-grained soil, the basic frost heave characteristics of the two basic processes of frost heaving are different. As we can see from Figures 8-12, the dividing line between the four stages of the basic process of frost heave of the gravel soil was different from that of finegrained soil. The frost heave amount and frost heave speed of gravel soil was also different from that of fine-grained soil. For the basic process of frost heave of gravel soil, the frost heave amount and frost heave speed of the four phases are different. By calculating the average frost heave speed at each stage, we can get the order of the frost heave speed in four stages, the second phase, the third phase, the first phase, and the fourth phase, which is in accordance with the actual frost heave process. The speed of frost heave in each phase essentially reflects the intensity of moisture migration in the soil and is also closely related to the temperature gradient [34]. In the early period of freezing, with the influence of the temperature gradient, the moisture migration is obvious under the effect of the stronger temperature gradient; thus, the greater frost heave increment is produced. In the middle and late freezing period, with the limited water under the closed water replenishing condition decreasing, the moisture migration is obviously eased even under the larger temperature gradient, and the frost heave amount gradually tends to be gentle. In order to effectively treat the frost heave deformation in occurrence, considering the different stages of the frost heave process of various soil samples, we think that the appropriate time points should be selected based on the basic characteristics of different soil frost heave, and the external water supplement should be cut off as far as possible to reduce the water migration in the soil.

The regression prediction formula shows that the initial water content has the most significant influence on the frostheaving ratio of sand and gravel soil. The research results of Nie et al. [32] on the frost heave characteristics of graded macadam also confirmed that water content is the dominant factor affecting the frost heave of graded crushed stone. Wang et al. [34] and other researchers pointed out that the main factors affecting the frost-heaving ratio of graded crushed stones were moisture content, followed by fine particle content, compactness, and cold end temperature. The regression analysis shows that the significant order of influence on the frost-heaving ratio of gravel soil is water content, clay content, compactness, and overlying load. This will help us to better understand the factors that affect the frost heave of gravel soil and provide suggestions for the antifrost heave of the engineering foundation.

\section{Conclusions}

The conclusions of this research are summarized as follows:

(1) Under the closed water replenishing condition, the frost-heaving ratio increased with initial moisture content linearly, rose with clay content corresponding to a polynomial function, gently decreased linearly with the increase of overlying load, increased first and then decreased with the increase of compactness in the form of polynomial function, and approached its maximum at the compactness of $95 \%$. Under the open water replenishing condition, the frost-heaving ratio of gravel soil can be found to 
increase several times more than that of the closed water replenishing condition.

(2) From the process of frost heave of gravel soil, it can be seen that there are approximately four phases: the frozen-shrink phase, the fast-increasing phase, the slow-increasing phase, and the relatively stable phase. The frost heave speed and the freezing speed of each phase are closely related. Moisture content distributions after freezing indicated that moisture migration during freezing occurred in the gravel soil sample. The moisture content in the frozen front section was significantly greater than initial moisture content, indicating the migration of moisture to the freezing front during freezing.

(3) Multifactor regression forecast formula was obtained by the multifactor regression analysis. It can be seen that the initial water content and clay content have great influence on the frost-heaving ratio of gravel soil under the closed water replenishing condition. The application of this regression model can predict the frost-heaving ratio under the comprehensive influence of different factors and has certain engineering application value.

(4) The effects of various factors on the frost-heaving ratio are water replenishing $>$ initial water content $>$ clay content $>$ compactness $>$ overlying load. Therefore, in the engineering practice, the control of water replenishing, initial water content, and clay content is the key method to conduct the antifreeze design. We suggest that the clay content of the soil foundation should be controlled below $15 \%$ and the compactness should be controlled over $98 \%$, so as to reduce the frost-heaving deformation of the gravel soil.

\section{Data Availability}

The data used to support the findings of this study are available from the corresponding author upon request.

\section{Conflicts of Interest}

We declare that the authors have no conflicts of interest or other interests that might be perceived to influence the results and/or discussion reported in this paper.

\section{Authors' Contributions}

Xiaoyong Long and Guoping Cen conceived and designed the research. Xiaoyong Long and Liangcai Cai carried out the experiment and analyzed the experiment results. Xiaoyong Long and Yue Chen wrote the manuscript. Xiaoyong Long, Guoping Cen, Liangcai Cai, and Yue Chen reviewed and edited the manuscript. All authors read and approved the manuscript.

\section{Acknowledgments}

This research was supported by China Civil Aviation Administration Research Project (MHRD20140216).

\section{References}

[1] H. M. Dai and X. L. Wang, "Frost heave susceptibility of highway bridge foundation in seasonal frost region," Cold Regions Science and Technology, vol. 20, no. 2, pp. 141-146, 1992.

[2] A. Y. Li, Y. H. Niu, F. J. Niu, and H. Liu, "Research status of frost heaving properties and controlling measures of coarse grained soil," Journal of Glaciology and Geocryology, vol. 1, no. 37, pp. 202-210, 2015.

[3] R. A. Peterson and W. B. Krantz, "Differential frost heave model for patterned ground formation: corroboration with observations along a North American arctic transect," Journal of Geophysical Research Biogeosciences, vol. 113, no. G3, pp. 250-258, 2014.

[4] M. W. Smith and D. E. Patterson, "Detailed observations on the nature of frost heaving at a field scale," Canadian Geotechnical Journal, vol. 26, no. 2, pp. 306-312, 1989.

[5] H. Liu, F. J. Niu, Y. H. Niu, Z. J. Lin, J. H. Lu, and J. Luo, "Experimental and numerical investigation on temperature characteristics of high-speed railway's embankment in seasonal frozen regions," Cold Regions Science and Technology, vol. 81, pp. 55-64, 2012.

[6] H. Liu, F. J. Niu, Y. H. Niu, and X. F. Yang, "Study on thermal regime of roadbed-culvert transition section along a high speed railway in seasonal frozen regions," Cold Regions Science and Technology, vol. 106-107, pp. 216-231, 2014.

[7] X. J. Zhang, "Analysis of frost heave laws in subgrade on Harbin-Dalian high-speed railway and its influence factors," Railway Standard Design, vol. 7, pp. 8-12, 2013.

[8] J. Y. Liu, G. P. Cen, and Y. Chen, "Study on frost heave characteristics of gravel soil pavement structures of airport in Alpine regions," RSC Advances, vol. 7, no. 40, pp. 2463324642, 2017.

[9] D. H. Everett, "The thermodynamics of frost damage to porous solids," Transactions of the Faraday Society, vol. 57, pp. 1541-1551, 1961.

[10] R. D. Miller, "Lens initiation in secondary frost heaving," in Proceedings of International Symposium on Frost Action in Soils, Lulea, Sweden, February 1977.

[11] N. Matsuoka, K. Moriwaki, and K. Hirakawa, "Diurnal frostheave activity in the Sør-Rondane Mountains, Antarctica," Arctic and Alpine Research, vol. 20, no. 4, pp. 422-428, 1988.

[12] N. Matsuoka, M. Abe, and M. Ijiri, "Differential frost heave and sorted patterned ground: field measurements and a laboratory experiment," Geomorphology, vol. 52, no. 1-2, pp. 73-85, 2003.

[13] R. L. Michalowski, "A constitutive model of saturated soils for frost heave simulations," Cold Regions Science and Technology, vol. 22, no. 1, pp. 47-63, 1993.

[14] T. F. Azmatch, D. C. Sego, L. U. Arenson, and K. W. Biggar, "New ice lens initiation condition for frost heave in finegrained soils," Cold Regions Science and Technology, vol. 82, pp. 8-13, 2012.

[15] J. B. Murton, "Thermokarst sediments and sedimentary structures, Tuktoyaktuk Coastlands, western Arctic Canada," Global and Planetary Change, vol. 28, no. 1-4, pp. 175-192, 2001.

[16] J. B. Murton, J. C. Ozouf, and R. Peterson, "Heave, settlement and fracture of chalk during physical modelling experiments with temperature cycling above and below $0^{\circ} \mathrm{C}$," Geomorphology, vol. 270, pp. 71-87, 2016.

[17] D. Sheng, S. Zhang, Z. Yu, and J. Zhang, "Assessing frost susceptibility of soils using PCHeave," Cold Regions Science and Technology, vol. 95, pp. 27-38, 2013. 
[18] J. Z. Zhou, C. F. Wei, H. Z. Wei, and L. Tan, "Experimental and theoretical characterization of frost heave and ice lenses," Cold Regions Science and Technology, vol. 104-105, pp. 76-87, 2014.

[19] H. Zheng, S. Kanie, F. J. Niu, and A. Y. Li, “Threedimensional frost heave evaluation based on practical Takashi's equation," Cold Regions Science and Technology, vol. 118, pp. 30-37, 2015.

[20] X. B. Chen, Y. Q. Wang, and P. He, "Frost susceptibility of sandy gravel during freezing," Chinese Journal of Geotechnical Engineering, vol. 10, no. 3, pp. 23-29, 1988.

[21] S. Taber, "Frost heaving," Journal of Geology, vol. 37, no. 5, pp. 428-461, 1929.

[22] J. Aguirre-Puente, M. Frémond, and G. Comini, "Congélation des sols-étude physique et modèles mathématiques," International Journal of Refrigeration, vol. 1, no. 2, pp. 99-107, 1978.

[23] T. S. Vinson, F. Ahmad, and R. Rieke, "Factors important to the development of frost heave susceptibly criteria for coarsegrained soils," Transportation Research Record, vol. N1089, pp. 124-131, 1986.

[24] X. B. Chen and Y. Q. Wang, "Control of frost heave in geotechnical engineering," in Proceedings of Eighth International Conference on Offshore Mechanics and Arctic Engineering, American Society of Mechanical Engineers (ASME), New York, NY, USA, March 1989.

[25] X. Z. Xu, "Progress of frost heave research in China," Advance in Earth Sciences, vol. 9, no. 5, pp. 13-19, 1994.

[26] P. Viklander, "Laboratory study of stone heave in till exposed to freezing and thawing," Cold Regions Science and Technology, vol. 27, no. 2, pp. 141-152, 1998.

[27] J. M. Konrad and N. Lemieux, "Influence of fines on frost heave characteristics of a well-graded base-course material," Canadian Geotechnical Journal, vol. 42, no. 2, pp. 515-527, 2005.

[28] J. M. Konrad, "Freezing-induced water migration in compacted base-course materials," Canadian Geotechnical Journal, vol. 45, no. 7, pp. 895-909, 2008.

[29] L. U. Arenson and D. C. Sego, "The effect of salinity on the freezing of coarse-grained sands," Canadian Geotechnical Journal, vol. 43, no. 3, pp. 325-337, 2006.

[30] Y. S. Ye, Z. J. Wang, A. J. Cheng, and M. Y. Luo, "Frost heave classification of railway subgrade filling material and the design of anti-freezing layer," China Railway Science, vol. 28, no. 1, pp. 1-7, 2007.

[31] Y. M. Lai, S. M. Zhang, and W. B. Yu, "A new structure to control frost boiling and frost heave of embankments in cold regions," Cold Regions Science and Technology, vol. 79-80, pp. 53-66, 2012.

[32] Z. H. Nie, Y. Liu, and X. Wang, "Experimental study on frozen-heave influence factors for graded gravel in surface layer of passenger dedicated line," Journal of Railway Science and Engineering, vol. 10, no. 4, pp. 59-62, 2013.

[33] H. X. Zhao, Z. Q. Wu, and Z. Y. Li, "Experimental study on frost heave of silty clay in seasonally frost soil regions," Procedia Engineering, vol. 28, pp. 282-286, 2012.

[34] Q. Z. Wang, J. K. Liu, X. X. Zhu, J. Y. Liu, and Z. Y. Liu, “The experiment study of frost heave characteristics and gray correlation analysis of graded crushed rock," Cold Regions Science and Technology, vol. 126, pp. 44-50, 2016.

[35] J. P. Bilodeau, G. Dore, and P. Pierre, "Gradation influence on frost susceptibility of base granular materials," International Journal of Pavement Engineering, vol. 9, no. 6, pp. 397-411, 2008.
[36] K. D. Eigenbrod, "Effects of cyclic freezing and thawing on volume changes and permeability of soft fine-grained soils," Canadian Geotechnical Journal, vol. 33, no. 4, pp. 529-537, 1996.

[37] R. Tester and P. Gaskin, "Effect of fines content on the frost susceptibility of a crushed limestone," Canadian Geotechnical Journal, vol. 33, no. 4, pp. 678-680, 1996.

[38] G. P. Cen, X. Y. Long, G. Hong, J. Y. Liu, and H. L. Li, "Influence of fine content on frost heaving properties of gravel soil," Science and Technology Review, vol. 5, no. 33, pp. 78-82, 2015.

[39] X. Y. Long, C. P. Cen, L. C. Cai, and J. Y. Chen, "Model experiment of uneven frost heave of airport pavement structure on coarse-grained soils foundation," Construction and Building Materials, vol. 188, pp. 372-380, 2018.

[40] JTG E40-2007, Test Methods of Soils for Highway Engineering, Ministry of Communication of the People's Republic of China, Beijing, China, 2007.

[41] W. J. Hou, "Analysis on the characteristic of temperature change in Dawu Town, Guoluo Prefecture," Guoluo Technology, no. 1, pp. 87-91, 2007.

[42] L. L. Yu and X. Y. Xu, "Experimental study on rate of frost heave by artificial freezing," Chinese Journal of Geotechnical Engineering, vol. 12, no. 31, pp. 1902-1906, 2009.

[43] T. L. Wang, Z. R. Yue, C. Ma, and Z. Wu, "An experimental study on the frost heave properties of coarse-grained soils," Transportation Geotechnics, vol. 1, pp. 137-144, 2014.

[44] R. Y. Li and J. Zhu, "Study for frost heave characteristics of deep overburden in double direction freezing mode," Coal Technology, vol. 36, no. 2, pp. 87-89, 2017.

[45] Y. Guo, Y. H. Yang, and L. G. Zeng, "Study on frost heaving characteristics of subgrade soil of Lanzhou-Xinjiang railway," Subgrade Engineering, vol. 149, no. 2, pp. 149-151, 2010.

[46] J. A. Bao, P. Yang, and X. N. Wang, "Experimental study on frost heave properties of cement-improved soil," Journal of Zhengzhou University (Engineering Science), vol. 34, no. 1, pp. 5-9, 2013. 


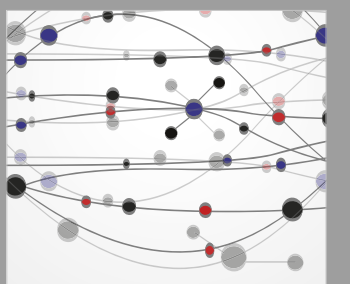

The Scientific World Journal
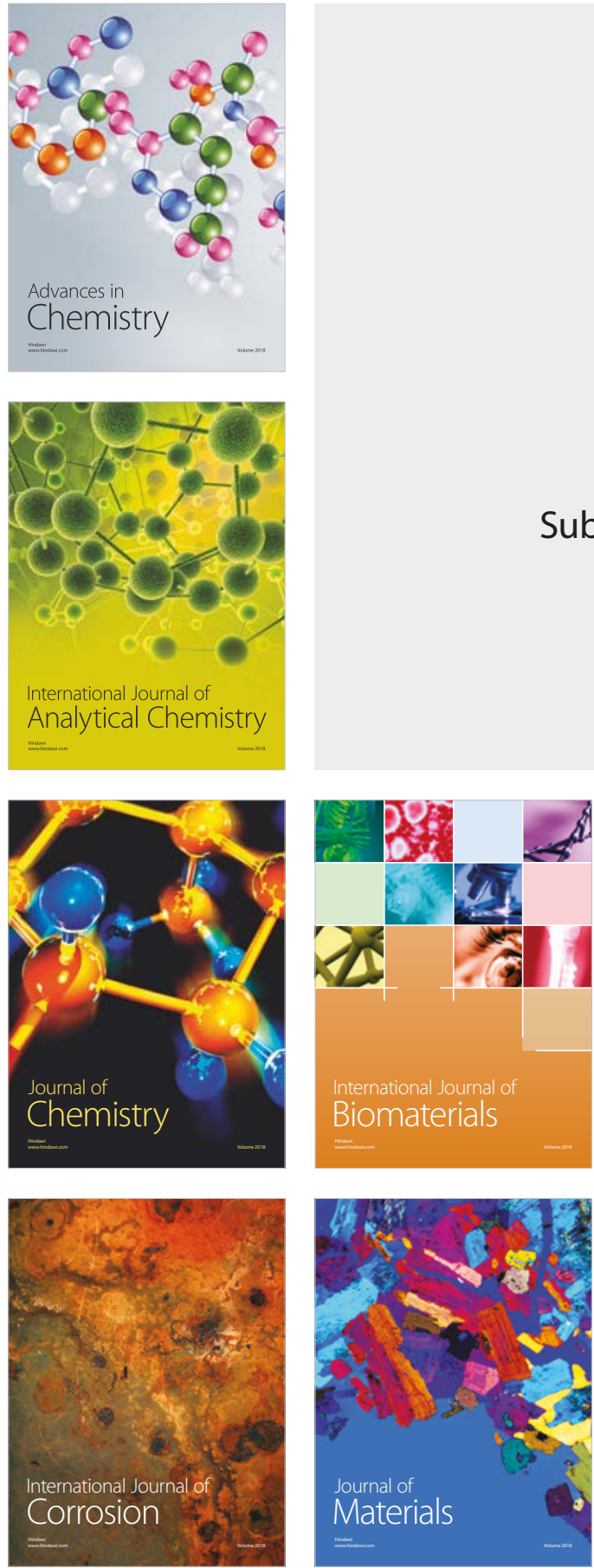

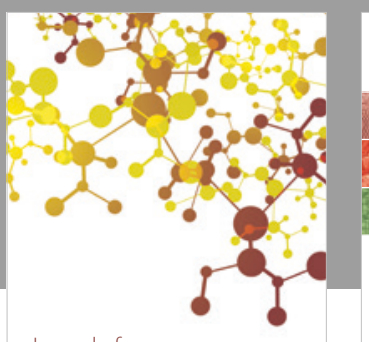

Journal of

Applied Chemistry
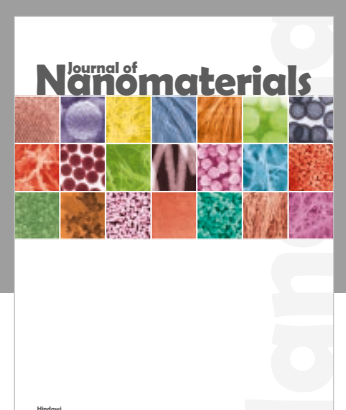

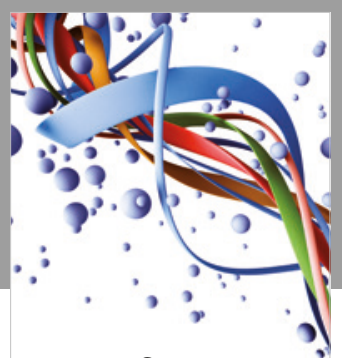

Scientifica

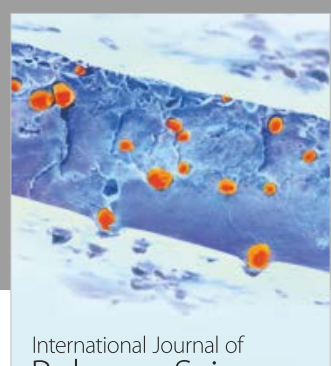

Polymer Science

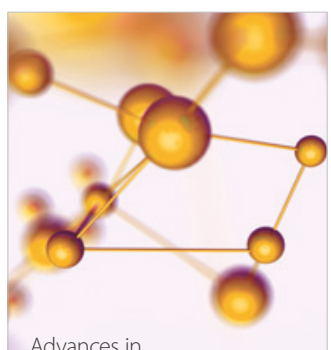

Physical Chemistry
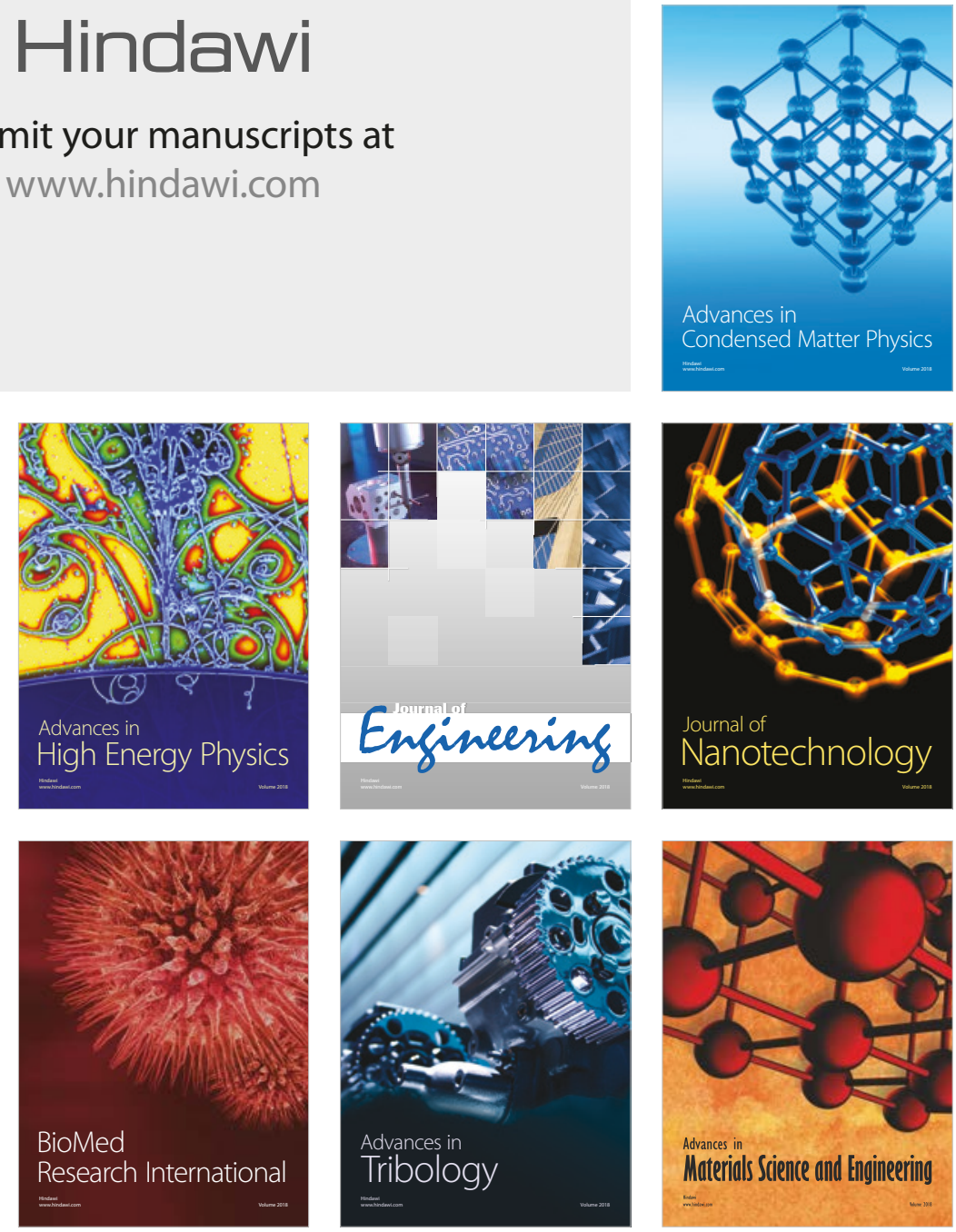